\title{
0 trabalho docente nos três primeiros anos do ensino fundamental a partir das relações sociais entre os professores e os outros sujeitos que constituem o cotidiano escolar
}

Camila Trindade ${ }^{1}$

\section{INTRODUÇÃO}

As relações sociais a partir da perspectiva sócio-histórica são compreendidas como processos que possibilitam o desenvolvimento e a formação da subjetividade dos indivíduos a partir do contexto histórico, social, político e cultural no qual os mesmos estão inseridos. Assim, como aponta Goés (2000, p. 121) "a construção social do indivíduo é uma história de relações com os outros", onde essas relações eu-outro são concretizadas por meio da linguagem, interações face á face, e por meio de relações sociais mais amplas, dentre essas as formas de inserção social e os lugares sociais.

Para além de considerar que os sujeitos são constituídos apenas pelas relações sociais em questão, afirma-se que a constituição e formação humana têm suas origens no processo de trabalho. Pois como afirma Marx (2013), a atividade do trabalho "é, antes de tudo, um processo entre o homem e a natureza, processo este em que o homem, por sua própria ação, medeia, regula e controla seu metabolismo com a natureza" (p.255). Além disso, através do processo de trabalho o homem também é transformado, pois ao agir "sobre a natureza externa e modificando-a por meio desse movimento, ele modifica, ao mesmo tempo, sua própria natureza" (MARX, 2013, p. 255).

Deste modo salienta-se que esses processos, das relações sociais e o trabalho, não são processos dissociáveis e autônomos aos indivíduos, mas sim devem ser compreendidos de forma dialética, ou seja, a partir dos seus movimentos de constituição.

Sendo assim, compreendendo que o trabalho e as relações sociais são processos relacionados buscou-se no presente estudo discutir o trabalho docente

\footnotetext{
${ }^{1}$ Mestranda do Programa de Pós-Graduação em Psicologia (PPGP) da Universidade Federal de Santa Catarina (UFSC). Psicóloga pela Universidade Federal do Rio Grande - FURG. (trindadecami@gmail.com).
} 
dos professores dos três primeiros anos do Ensino Fundamental a partir das relações sociais que estes estabelecem com os outros sujeitos escolares.

\section{METODOLOGIA}

A construção do presente estudo foi baseada na perspectiva da Psicologia Sócio Histórica, a qual busca compreender os fenômenos e os sujeitos em quanto processos históricos e sociais. Nesta perspectiva nossos pressupostos foram baseados em Freitas (2002) e Molon (2008) para compreender o processo de pesquisa e em Zanella et al. (2007) para compreender constituição do sujeito.

A opção por essa abordagem teórico-metodológica se deu em função da mesma permitir a compreensão das relações sociais que se estabelecem entre os sujeitos bem como o próprio trabalho docente, em quanto suas formas históricas e sociais e partir dos seus movimentos de constituição.

Para o desenvolvimento do presente trabalho inicialmente foi realizada uma revisão bibliográfica referente a temática do trabalho docente, do trabalho docente nos três primeiros anos do Ensino Fundamental e sobre as relações sociais a fins de subsidiar a construção e apropriação do conhecimento nessa área do conhecimento.

Para investigar como se estabeleciam as relações dos professores dos três primeiros anos, foram realizadas entrevistadas semiestruturadas respectivamente com a professora do primeiro ano, do segundo e do terceiro ano. $O$ tempo para a realização dessa atividade com as professoras variou por diferentes motivos, entre esses, a ausência de outro professor que iria substituir as respectivas professoras nas atividades com as crianças. Sendo que as entrevistas tiveram tempo mínimo de treze minutos e máximo de quarenta minutos e foram realizadas entre os meses de junho e julho do ano de 2015.

As professoras entrevistadas compõem o quadro trabalhadores de uma Escola de Ensino Fundamental da rede pública municipal de educação da cidade do Rio Grande localizada no estado do Rio Grande do Sul. Deve-se destacar ainda que para a realização das entrevistas contou-se com o consentimento da gestão da referida escola e com o Termo de Consentimento Livre Esclarecido das professoras.

Posteriormente a realização das entrevistas as mesmas foram transcritas e submetidas á de análise de conteúdo que representa um conjunto de técnicas e 
procedimentos que permite compreender os contextos e sentidos de produção dos conteúdos (FRANCO, 2008).

A partir da técnica da análise de conteúdo foram estabelecidas diferentes unidades de análises que representam os conteúdos expressos pelos relatos das professoras. Tendo em vista que o presente trabalho é um recorte dos resultados da pesquisa do Trabalho de Conclusão do Curso de Psicologia, foram apresentadas e discutidas as unidades de análise que referentes ao trabalho docente a partir das relações sociais das professoras dos três primeiros anos com os outros sujeitos escolares, neste caso, os alunos, professores, a gestão escolar e os responsáveis pelos alunos.

\section{RESULTADOS E DISCUSSÕES}

Evidencia-se inicialmente uma característica geral quanto aos relatos sobre as relações entre os professores e os outros sujeitos que fazem parte do cotidiano escolar. A qual se refere ao fato de que nesses relatos os professores enfatizaram a descrição de seus comportamentos e suas expectativas quanto a esse processo, mais do que propriamente como se desenvolviam essas relações no cotidiano escolar e suas implicações no trabalho docente.

Desde modo com o intuito de compreender o trabalho docente dos professores dos três primeiros anos do Ensino Fundamental a partir das relações sociais que estes estabelecem com os outros sujeitos escolares, se fez necessário inicialmente evidenciar essas relações para posteriormente compreender como estas constituíam e davam forma ao trabalho docente.

Para isso, serão abordadas e discutidas nos próximos itens as relações entre professores e alunos, as relações entre os professores e os outros professores dos anos iniciais, as relações entre professores e a gestão escolar, as relações entre professores e os responsáveis dos alunos e por fim as articulações entre essas relações e a constituição do trabalho docente dos respectivos professores.

\section{AS RELAÇÕES ENTRE PROFESSORES E ALUNOS}

A relação entre professores e alunos, assim como dos professores para com sua profissão é uma relação afetiva (TARDIF; LESSARD, 2011). As professoras entrevistadas demostraram que estabelecem relações de afetividade com os seus 
alunos, mais especificamente descrevendo os seus diferentes comportamentos para com eles, entre esses rígidas, sinceras ou "durona":

Como eu te falei eu sempre fui muito sincera, de sempre falar quando eu vejo alguma coisa errada, de corrigir... (Professora $1^{\circ}$ ano).

Então quando eu tenho que ser rígida eu sô, quando tem que ser carinhosa, eu sou carinhosa. Ao mesmo tempo, que eu estou sorrindo e fico séria, eles já sabem que a tia ficou séria, é porque, a tia não está gostando de alguma coisa. (Professora $1^{\circ}$ ano)

A eu sou bem durona, mas eles gostam... (Professora $2^{\circ}$ ano).

Sabe, eles procuram sempre assim sabe, ai tia, olha, o meu caderno vê como que tá?! Eu digo, tá lindo, tá ótimo e tal! Excelente, como tu melhorasse! Tu te da conta como tu melhorou? (Professora $3^{\circ}$ ano).

Esses comportamentos apesar de serem particulares possuem uma finalidade em comum, a qual seria cumprir com a função de trabalho que estas professoras desempenham no contexto educacional. Ou seja, a função de educadoras que segundo elas tem como objetivo propiciar o desenvolvimento dos processos de aprendizagens das crianças. Seguem alguns trechos que retratam este processo:

Eu acho que o meu papel de professora também não é ver as coisas e não corrigir. (Professora $1^{\circ}$ ano).

Eu sou amiga, né mas eu também quero que eles percebam que eu sou a professora e que eu tô ali para ensinar eles. (Professora $2^{\circ}$ ano).

Para cumprir o meu papel... Em quanto educadora. (Professora $2^{\circ}$ ano).

Então isso, eles se dão conta do avanço e se incentivam os outros, bá olha que pintura bonita fulano... De acordo com as suas habilidades e com o seu crescimento individual. Então eu valorizo isso em cada um e eles passam a valorizam no colega também. (Professora $3^{\circ}$ ano).

Desde modo as professoras evidenciaram os modos como compreendem que estão cumprindo com a sua função de educadora, que no caso vão desde a correção dos erros dos alunos como afirma a professora do primeiro ano, até o incentivo e a valorização da criança no processo de ensino-aprendizagem.

\section{AS RELAÇÕES ENTRE OS PROFESSORES E OS OUTROS PROFESSORES DOS ANOS INICIAIS}


As professoras entrevistadas foram questionadas sobre como se estabeleciam as relações entre elas com os outros professores dos anos iniciais: "Eu gostaria que tu comentasse um pouco também como é tua relação com os outros professores dos anos iniciais?".

Porém, o que chamou a nossa atenção foi o fato de que na descrição sobre essas relações elas descreveram exclusivamente como se relacionavam com os outros professores que trabalhavam respectivamente nos mesmos anos que elas trabalhavam. Ou seja, a professora do primeiro ano se referiu a sua relação com a outra professora do primeiro ano, a professora do segundo ano se referiu a sua relação com a outra professora do segundo ano e a do terceiro ano se referiu a sua relação com a outra professora do terceiro ano, como observamos nos seguintes relatos:

\begin{abstract}
Eu trabalho em conjunto com a outra professora do primeiro ano! É assim tudo o que nós trabalhamos, nós trabalhamos em conjunto! Não só com essa professora, todas as outras professoras que estiveram ai no primeiro ano, eu sempre trabalhei em conjunto. (Professora $1^{\circ}$ ano).

Agora eu arranjei uma parceira boa (se referindo a outra professora do segundo ano) que a gente consegue fazer um trabalho conjunto, eu e a minha outra colega. [...] Que a gente está meio que fazendo uns trabalhos... uns mini-projetos assim com eles né, ai já fizemos um projeto sobre a água e agora a gente está num projeto sobre animais... E ai... tá indo né, mas antes eu fazia né, eu planejava as minhas aulas, seguia um conteúdo programático, né um conteúdo que a gente recebe. (Professora $2^{\circ}$ ano).

E a gente tem essa coisa assim, da troca, chega com a outra professora boa (se referindo a outra professora do terceiro ano), olha fiz essas folhinhas e ai a gente vai dividindo... Mesmo que não tenha muito tempo para isso, a gente acaba que dividindo, compartilhando, se ajudando... Acho muito bacana. (Professora $3^{\circ}$ ano).
\end{abstract}

Essas relações evidenciadas se mostram ser construtivas e positivas tanto ao desenvolvimento do trabalho docente, bem como a própria motivação das professoras sobre o processo de trabalho. Apesar de haver por parte das professoras entrevistadas essa predominante descrição sobre com quem estabelecem essas relações, como citado anteriormente, elas ainda evidenciam que mantém uma boa relação com os outros professores dos anos iniciais, sendo que as professoras do segundo e do terceiro ano inclusive destacam a necessidade de construção de outros espaços e momentos para dialogar e produzir junto com os outros docentes. 
Então assim, eu sinto falta desse momento, dessa troca, que a gente não consegue trocar. $E$ também a falta do momento de trocar com o do primeiro... Que eu não sei... né! Para mim, mais ou menos saber como esse aluno vai chegar em mim. [...] E de trocar com o terceiro, porque a minha preocupação é como é que eu tenho que deixar o meu aluno, para o próximo ano. (Professora $2^{\circ}$ ano).

E mesmo assim, com hora atividade, eu acho que deveria ter mais tempo para as nossas trocas. (Professora $3^{\circ}$ ano).

\section{AS RELAÇÕES ENTRE OS PROFESSORES E A GESTÃO ESCOLAR}

Quanto a relação que as professoras entrevistadas estabelecem com a gestão escolar, as mesmas foram descritas como positivas principalmente na medida em que a gestão se apresentava como receptiva e acolhedora as demandas apresentadas pelas professoras.

É assim, normal... Eu sempre... nunca tive problema nenhum, quando precisei me direcionar para a direção com algum problema, sempre, coloco com antecedência, tudo é resolvido, normal. (Professora $1^{\circ}$ ano).

É tranquila, eu não tenho problema assim... (Professora $2^{\circ}$ ano).

Bá, eu não posso assim falar nada! As gurias assim, extremamente compreensivas [...] (Professora $3^{\circ}$ ano).

Apesar desta aparente tranquilidade e reciprocidade que se estabelece entre as professoras e a gestão, evidenciou-se principalmente por meio do relato da professora do segundo ano alguns desencontros e instabilidades nessas relações. Neste caso desta professora o que observa-se é um desencontro de falas e posições que acabam por contradizem a postura da professora frente a situação em questão. Sendo que isso na compreensão da professora faz com ela tenha sua posição questionada e tornada não legitima.

A me incomoda assim, "oh", a questão... Parece que a gente nunca tem razão, nem, em questão de tu fazer queixa de um aluno... Poxa! Não tá dando [...] E ai estão sempre meio que... Para não se incomodar com os pais, dão... passam a mão por cima do aluno. $\mathrm{E}$ ai a tua figura em quanto professora, naquele momento se perde todinha, né. Se eu chamo a atenção e questiono em sala de aula, mas chega lá na direção e ninguém faz nada, fica todo mundo quieto então... É sinal que eu posso fazer o que eu quiser na sala de aula... (Professora $2^{\circ}$ ano).

Devido a estas situações a professora do segundo ano afirmou que passa a repensar de modo individual algumas práticas que envolvem o seu trabalho, 
principalmente quando não são atendidas ou não possuem uma resposta adequada da escolar sobre as suas demandas.

Mas assim quando eu tenho algum problema eu sempre tento, não passar para a direção, né! [...] Tentar resolver eu, chamando um pai para conversar. [...] Ai eu antes de passar para a direção, eu nem passo, já chamei a mãe para conversar... A mãe já falou que levou na fonodiologa, tudo... (Professora $2^{\circ}$ ano).

\section{AS RELAÇÕES ENTRE OS PROFESSORES E OS RESPONSÁVEIS DAS CRIANÇAS}

Por meio da descrição das professoras sobre como estas estabelecem suas relações com os familiares de seus alunos, pode-se observar que estes são participativos no processo de escolarização das crianças. Seja por meio de cobranças, opiniões, reclamações e elogios de diferentes modos e as suas maneiras os familiares procuram participar e se fazer presente nesse processo.

É até alguns pais... Porque os pais, nós cobram muito, tia e o trabalhinho? Não tem trabalhinho? Tem! Hoje, foi dado uma folhinha, mas só naquela folhinha teve várias coisas antes de chegar naquela folhinha... (Professora $1^{\circ}$ ano).

E os pais aqui são muito mais presentes do que lá, que é particular (comparando em relação a outra escola particular em que trabalha). Lá eu tenho pai, que eu nem conheço, e nós já estamos em julho. Eu nunca vi o rosto do pai, eu nem sei quem são... não sei nem o que fazem, nada. E aqui é diferente, aqui eles ainda buscam na escola... Embora tenham alguns que vão de van. Se tu chama para um atendimento vem, se tu chama para uma entrega de avaliações vem... Então são bem mais presentes que lá. (Professora $2^{\circ}$ ano).

Fiquei muito feliz esse ano! Hoje nessa turma, todos... eu fui entregar os pareceres, todos compareceram e eu pude conversar com cada um em especial e pedir... (Professora $3^{\circ}$ ano).

Devido a essa participação direta ou indiretamente dos familiares das crianças as professoras afirmaram que buscam explorar essas relações para efetivar o processo de ensino aprendizagem das crianças.

Ah, não, não... Eu tenho, eu sempre procurei eu sempre procurei trazer os pais, para perto de mim, para trabalhar junto principalmente na alfabetização. $\mathrm{Na}$ alfabetização, tem que ter um elo, muito grande, entre a família e o professor. Tem que ter esse contato, eu faço os pais trabalharem junto comigo! (Professora $1^{\circ}$ ano). 
Olha eu sou uma pessoa assim que eu sempre fui muito sincera! Não sou, não gosto de ficar enrolando, dizendo palavras bonitas só para agradar os pais, hã, isso em algumas fases da minha vida me trouxe até problemas. (Professora $2^{\circ}$ ano).

É! Isso, é importante. Não existe trabalho de educação sem a família estar presente, sem a escola ter esse contato com a comunidade! (Professora $3^{\circ}$ ano).

\section{O TRABALHO DOCENTE A PARTIR DAS RELAÇÕES SOCIAIS ENTRE OS DIFERENTES SUJEITOS ESCOLARES}

Para além de evidenciar a dinâmica das relações sociais que se estabelecem entre os professores dos três primeiros e os outros sujeitos escolares, a análise destas relações permitiram a compreensão de alguns aspectos que constituem o trabalho docente destes professores.

Assim, as relações que se estabelecem entre os professores e os alunos nos evidenciaram que $o$ trabalho docente é envolvido por sentimentos e comportamentos específicos, como citado anteriormente, por exemplo, a rigidez e a amizade. Sendo que esses comportamentos constituem e particularizam o trabalho do professor, mas não impedem que as professoras desenvolvam o trabalho voltado para o que é esperado socialmente para a sua profissão, como elas citaram que o papel do professor é de corrigir os erros e incentivar os alunos no processo de aprendizagem.

As relações que se estabelecem entre as professoras entrevistadas com os outros professores, permitiu assinalar que o trabalho docente das mesmas é realizado e construído a partir de práticas de parcerias e trocas entre os professores. Porém as práticas de trabalho com os professores que elas estabelecem são exclusivamente com professores que trabalham nos respectivos anos em que elas trabalham, ou seja, professora do primeiro ano trabalha com a outra professora do primeiro ano e assim sucessivamente. Sendo que as professoras entrevistadas se dão conta dessa realidade e inclusive apontam a necessidade de espaços e momentos de diálogos com os professores dos outros anos.

As professoras entrevistadas na maioria das vezes passam a tomar decisões que envolvem o seu trabalho de modo isolado, sem consultar a gestão escolar. Este fato ocorre devido ao que as professoras apontam como falta de autoridade da gestão escolar na resolução dos problemas e dificuldades que 
extrapolam o controle do professor, como citado anteriormente o caso da professora do segundo ano.

Por fim, devido ao fato da participação/preocupação dos responsáveis na escolarização das crianças as professoras buscam aprimorar esse vínculo no sentido de buscar trabalhar em conjunto com os responsáveis para assim potencializar o processo de ensino-aprendizagem das crianças. Pois, como citado anteriormente e sintetizado pela professora do terceiro ano, na concepção das entrevistadas, não existe trabalho de educação sem os responsáveis.

\section{CONSIDERAÇÕES FINAIS}

Não se pretende no presente trabalho esgotar as discussões acerca das temáticas discutidas. Assim, foram apresentados alguns pontos das relações que se estabelecem entre esses processos, tendo em vista que os mesmos não são considerados como fenômenos isolados, mais sim estão em constante movimento e constituição.

Nesta perspectiva a análise das relações sociais que se estabelecem entre os professores dos três primeiros anos do Ensino Fundamental e os outros sujeitos escolares, permitiu evidenciar algumas particularidade e formas que 0 trabalho docente destes professores assume no cotidiano escolar.

Estas relações foram possíveis de se estabelecer pois, na medida que os professores relatam como são suas relações com os outros explicitam também como agem e o que pensam sobre o seu processo de trabalho.

Devido a observação desses movimentos que pode-se afirmar que a compreensão do trabalho docente dos professores dos três primeiros anos do Ensino Fundamental também perpassa pela compreensão e análise das relações que se estabelecem entre esses professores com os outros sujeitos escolares. Sendo que para além disso, essas análises apontam ainda demandas relacionadas ao trabalho docente que devem ser revistas e repensadas.

\section{REFERÊNCIAS}

FRANCO, M.L.P.B. Análise de Conteúdo. 3 ed. Brasília: Liber Livro. 2008. 
FREITAS, M. T. de A. A abordagem sócio-histórica como orientadora da pesquisa qualitativa. Cadernos de Pesquisa, jul. 2002, no.116, p. 21-39.

GÓES, M. C. R. A formação do indivíduo nas relações sociais: Contribuições teóricas de Lev Vigotski e Pierre Janet. Educação \& Sociedade, v. XXI, n.71, 2000. p. 116-131. Disponível em: <http://www.scielo.br/pdf/es/v21n71/a05v2171.pdf> Acesso em: 12 maio 2016.

MARX. K. O capital: Crítica da economia política: Livro I. São Paulo: Boitempo, 2013.

MOLON, S. I. Questões metodológicas de pesquisa na abordagem sócio-histórica. Revista Informática na educação: teoria \& prática, jan./jun. 2008, vol.11, no.1, p. 56-68.

TARDIF, M.; LESSARD, C. O trabalho docente: elementos para uma teoria da docência como profissão de interações humanas. 6를 $\mathrm{Ed}$. Rio de Janeiro: Vozes, 2011.

ZANELLA, A. V. et. al. Questões de método em textos de Vygotski: contribuições à pesquisa em Psicologia. Psicologia \& Sociedade, v.2, n.19, 2007. p.25-33. Disponível em: <http://www.scielo.br/pdf/psoc/v19n2/a04v19n2.pdf> Acesso em: 12 maio 2016. 